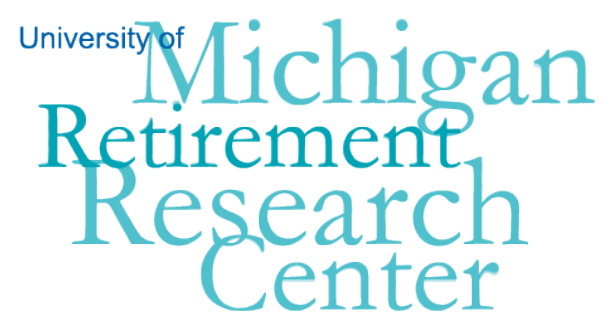

Working Paper WP 2014-267

\title{
Is the 2010 Affordable Care Act Minimum Standard to Identify Disability in All National Datasets Good Enough for Policy Purposes?
}

\author{
Richard V. Burkhauser, T. Lynn Fisher, Andrew J. Houtenville \\ and Jennifer R. Tennant
}

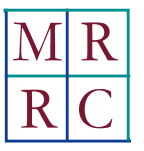

Project \#: UM12-14 



\title{
Is the 2010 Affordable Care Act Minimum Standard to Identify Disability in All National Datasets Good Enough for Policy Purposes?
}

\author{
Richard V. Burkhauser \\ Cornell University and University of Melbourne \\ T. Lynn Fisher \\ Social Security Administration \\ Andrew J. Houtenville \\ University of New Hampshire \\ Jennifer R. Tennant \\ Ithaca College \\ March 2014 \\ Michigan Retirement Research Center \\ University of Michigan \\ P.O. Box 1248 \\ Ann Arbor, MI 48104 \\ www.mrrc.isr.umich.edu \\ (734) 615-0422
}

\section{Acknowledgements}

The research reported herein was performed pursuant to a grant from the U.S. Social Security Administration (SSA) funded as part of the Retirement Research Consortium through the Michigan Retirement Research Center (Grant \# 5 RRC08098401-04-00). The findings and conclusions expressed are solely those of the authors and do not represent the opinions or policy of SSA or any agency of the Federal Government or the Michigan Retirement Research Center. Additional funding was received from the Rehabilitation Research and Training Center on Disability Statistics and Demographics at Hunter College, which is funded by the National Institute on Disability and Rehabilitation Research (NIDRR, Federal Award \# H133B120006); the contents of this paper do not necessarily represent the policy of NIDRR and readers should not assume endorsement by the Federal Government (Edgar, 75.620 (b)). 


\begin{abstract}
Using linked 2009 Current Population Survey (CPS)-Annual Social and Economic Supplement/Social Security Administration records data and a definition of disability based on the six-question disability sequence (6QS) in the CPS-Basic Monthly Survey we perform a face validity test that shows that the 6QS captures only 66.3 percent of those who administrative records confirm are receiving Social Security benefits based on their disability. Adding a workactivity question to the 6QS increases our capture rate by another 23.1 percentage points for a total of 89.3 percent. We find little difference in the distribution of conditions between those who only report a 6QS-based disability and those who only report a work activity-based disability. The four function-related questions in the 6QS do a relatively good job of capturing those receiving benefits based on these conditions. But the work-activity question does a far better job of capturing those receiving benefits than the two activity-related questions in the 6QS.
\end{abstract}

\title{
Citation
}

Burkhauser, Richard V., T. Lynn Fisher, Andrew J. Houtenville and Jennifer R. Tennant (2014). "Is the 2010 Affordable Care Act Minimum Standard to Identify Disability in All National Datasets Good Enough for Policy Purposes?” Ann Arbor MI: University of Michigan Retirement Research Center (MRRC) Working Paper, WP 2014-267. http://www.mrrc.isr.umich.edu/publications/papers/pdf/wp267.pdf 


\section{Introduction}

The Americans with Disabilities Act of 1990 was the culmination of a decades-long effort to afford people with disabilities the same protections against discrimination that the Civil Rights Act of 1964 or subsequent civil rights legislation provided those facing discrimination based on race, national origin, sex, and age. ${ }^{1}$ Unlike these other protected classes, whose characteristics are immutable or relatively easy to determine, disability is not an immutable characteristic. Hence, it is a more difficult characteristic to conceptualize and operationalize for purposes of affording civil rights protection and, more generally, for statistical purposes including the monitoring of the health, employment, and economic well-being of this protected class. (See Jette and Bradley, 2002, and Mathiowetz, 2002, for reviews of the conceptual and methodological issues in measurement of work disabilities.)

To provide the information for evidence-based public policymaking it is necessary for researchers both inside and outside government agencies to have sufficient data to capture the effect of current and future policies on the classes of citizens that, based on past discrimination or current circumstances, require targeted government actions. With respect to people with disabilities this has meant efforts by government statistical agencies to develop a set of questions that could, within more general national datasets, identify the population with disabilities in a manner similar to the questions used to identify people by race, ethnicity, gender, and age.

In what is considered a milestone in the effort to determine a minimum standard for the set of questions required to identify disability in all national datasets, Section 4302 of the Affordable Care Act (ACA) of 2010 mandates the establishment of standards for the collection

\footnotetext{
${ }^{1}$ While the Civil Rights Act of 1964 (P.L. 88-352) did not prohibit discrimination based on age, discrimination in hiring and promotions against people who are age 40 or older was prohibited by the Age Discrimination in Employment Act of 1967 (ADEA, P.L. 90-202).
} 
and dissemination of health statistics for five specific demographic sub-populations: race, ethnicity, gender, primary language, and disability status.

In response to this mandate, in October 2011, the U.S. Department of Health and Human Services (HHS) established new minimum data collection standards for these sub-populations, in which the new six-question sequence on disability (6QS) that was introduced in the American Community Survey (ACS) and is currently used in the Current Population Survey (CPS), was deemed "the data standard for survey questions on disability" (HHS, 2011, p. 7). The first four questions of the 6QS are function-based, focusing on: hearing, vision, cognition (concentrating, remembering, or making decisions), and mobility (physical matters like walking and climbing stairs). The last two are activity-based, relating to activities of daily living (dressing or bathing) and instrumental activities of daily living (doing errands alone such as visiting a doctor's office or shopping). See Appendix Table 1 for their specific wording and that of other variables.

The American Housing Survey (AHS), National Health Interview Survey (NHIS), the incoming rotations of the CPS-Basic Monthly Survey (CPS-BMS) and the American Time Use Survey (ATUS) include the 6QS. The Survey of Income and Program Participation (SIPP) is considering it for its core. In their report, HHS cites the use of the 6QS in national surveys and the Office of Management and Budget's encouragement of other federal agencies to use the 6QS because of the "extensive testing used in the development of these measures, including the findings that alternative measures did not test as well” as part of their justification for making it "the data standard for survey questions on disability” (HHS, 2011, p. 7-8).

We build on the work of Burkhauser, Houtenville and Tennant (forthcoming), who evaluate Type 2 error (false negatives) in the 6QS responses of people on the CPS-BMS based on their responses with respect to receiving either Social Security Disability Insurance (SSDI) or 
Supplemental Security Insurance—Disabled Adult (SSI-Disabled Adult) on the Current Population Survey-Annual Social and Economic Supplement (CPS-ASEC). ${ }^{2}$ Using Social Security Administration (SSA) administrative records data, we provide additional evidence that the lack of a work-activity question in the 6QS results in its inability to capture a substantial portion of the population with disabilities that should be included in any working-age population with disabilities—-those currently receiving Social Security benefits based on their disability. Because this Type 2 error only comes from a population of current program recipients who do not answer "yes" to the 6QS, our approach understates the number of Type 2 errors. That is, we are unable to capture Type 2 error arising from those who do not answer "yes” to the 6QS, have disabilities but are not currently receiving SSDI/SSI-Disabled Adult benefits.

Our face validity test uses linked 2009 CPS-ASEC/SSA administrative records data. We find that the 6QS captures only 66.3 percent of those who administrative records confirm are receiving Social Security benefits based on their disability. When we add a work-activity question to the 6QS, as recommended by Burkhauser et al. (forthcoming) based on their findings using self-reported measures of disability income receipt, our capture rate increases by another 23.1 percentage points—-for a total of 89.3 percent.

Furthermore, we find little difference in the distribution of conditions between those who only self-report a 6QS-based disability and those who only self-report a work activity-based disability. Each of the four function-related questions in the 6QS do a relatively good job of capturing those receiving Social Security benefits based on a condition the literature suggests is

\footnotetext{
${ }^{2}$ They do not address Type 1 error (false positives) because there is not a convenient sample of individuals known to not have a disability, since individuals not receiving SSDI/SSI-Disability income may or may not have a disability. Even those whose SSDI/SSI-Disability applications have been rejected cannot be known to not have a disability. Past denial of benefits is not a suitable method of identifying absence of disability.
} 
related to that function. But the work-activity question does a far better job of capturing those receiving Social Security benefits than the two activity-related questions in the 6QS.

In 2006, Sallie Keller-McNulty, the then-President of the American Statistical Association, urged that research on technical and methodological adjustments to a work-activity question continue so that it could be added to the ACS to improve the measurement of work disability (Keller-McNulty, 2006). We find that a work-activity question in combination with the 6QS substantially improves the ability to identify a disability subpopulation that should be included in any population of working-age people with disabilities—-those receiving Social Security benefits based on their disability. We conclude that the addition of some form of workactivity question would substantially improve the ability of national datasets to capture this important part of the working-age population with disabilities.

\section{Concepts of Disability}

There is no universal agreement on the most appropriate definition of disability, although the World Health Organization's International Classification of Disability, Health and Functioning (ICF) (WHO, 2001) is a commonly used framework for defining disability. This conceptual framework recognizes disability as a dynamic process that involves the interaction of a person's health condition and personal characteristics with their physical and social environments. The emergence of the ICF as a systematic and comprehensive way of conceptualizing the population with disabilities has resulted in an international effort to use these classifications to better identify the population with disabilities in government-sponsored datasets (Swanson, Carrothers, and Mulhorn, 2003).

In the ICF framework, a health condition is a prerequisite for a disability. Examples of health conditions are listed in the International Classification of Diseases, Tenth Edition (ICD- 
10), and they encompass diseases, injuries, health disorders, and other health-related conditions. An impairment is defined as a significant deviation or loss in body function or structure resulting from a health condition. An activity limitation is defined as the difficulty an individual may have in executing activities. A participation restriction is defined as an issue that an individual may experience in a life situation, perhaps due to the physical or social environment. In the ICF framework, the term disability describes the health condition-based presence of an impairment, activity limitation, and/or participation restriction.

A major challenge is how to operationally identify a random sample of this complex conceptualization of the population with disabilities in a national survey where questionnaire space is highly constrained. One way to describe how the CPS-ASEC may be used to do so is to imagine a square containing the entire population with health conditions (see Figure 1). Within the square are three concentric circles (i.e., in the shape of an archery target), with the outermost circle representing people with disabilities using ICF concepts (that is, having health conditionbased impairments, activity limitations, or participation restrictions), the middle circle representing those with work-activity limitations (a subset of the broader ICF-defined population), and the innermost circle representing people currently receiving Social Security benefits based on their disability (a subset of the work-activity limited population whose limitations are severe enough to prevent them from performing "any substantial gainful activity"-that is, a sub-population whose work-activity limitations are severe enough to meet the eligibility criteria for these permanent and total Social Security disability programs).

Burkhauser et al. (forthcoming) show that although the outermost circle is the concept of disability that the 6QS is attempting to operationally achieve, the 6QS-based and work-activity disability populations are best described by a Venn diagram with the majority of people either 
responding "yes" to one of the 6QS questions and "no" to the work-activity question or vice versa, and only a minority responding “yes” to both. More importantly, as we will discuss in more detail, when we use SSA administrative records linked to the CPS data to determine more precisely who is currently receiving Social Security income based on their disability (as opposed to the self-reporting of disability benefits), our Venn diagram of that population shows that only 66.3 percent of these beneficiaries who should be included in any conceptualization of the disability population are captured by the 6QS alone.

\section{Data and Key Variables}

Burkhauser et al. (forthcoming) were the first to use data from the public-use CPS to show how sensitive the size and socioeconomic characteristics of the working-age population with disabilities are to the questions used to capture that population. They proposed a face validity test of the relative merits of each. That is: How well do the questions capture a subpopulation that should be included in any formulation of working-age people with disabilities_current Social Security Disability Insurance (SSDI) and Supplemental Security Income for disabled adults (SSI-Disabled Adult) income recipients? ${ }^{3}$

However, they based their conclusions on results using the 2010 public-use CPS data that only contains self-reported information on receipt of Social Security income. Here we use two datasets: (1) the 2009 public-use CPS-ASEC and (2) 2009 public-use CPS-ASEC data matched to SSA administrative records, which was the most recent matched data available. These matched data provide much more accurate information on who in the CPS data is currently receiving Social Security benefits based on their disability and the main diagnosis (medical listing) on which that disability is based.

\footnotetext{
${ }^{3}$ This is a measure of Type 2 error. They do not address Type 1 error (false positives) because there is not a convenient sample of individuals known to not have a disability, since individuals not receiving SSDI/SSI-Disabled Adults income may or may not have a disability.
} 
General Information About the CPS. The CPS is a joint undertaking of the Bureau of Labor Statistics (BLS) and the Census Bureau. It is a monthly survey of approximately 57,000 households and is the primary source of labor force information for the U.S. working-age (16 years and over), non-institutionalized population. ${ }^{4}$ The CPS-BMS data contain labor force information and demographic information, and since June 2008 include a series of six disability questions—see Appendix Table 1. In June 2008, the 6QS was asked of all respondents in that month-in-sample. Thereafter it was asked in the respondents' first and fifth months-in-sample (CPS, 2009b). As can be seen in Appendix Table 1, the first four questions are function-based, focusing on: hearing, vision, cognition (concentrating, remembering, or making decisions), and mobility (physical matters like walking and climbing stairs). The last two are activity-based, relating to activities of daily living (dressing or bathing) and instrumental activities of daily living (doing errands alone such as visiting a doctor's office or shopping).

Prior to 2008, the American Community Survey (ACS) included a work-activity question as part of its original 6QS. But this question was dropped in 2008. The CPS-BMS 6QS which is patterned after the 2008 ACS also does not include a work-activity question, although a workactivity question has been asked in the CPS-ASEC (a.k.a., March supplement) since 1981. (See: Appendix Table 1).

The March supplement provides the usual monthly labor force data provided in the BMS, but also adds data on work experience, income, non-cash benefits, and migration (CPS, 2009a). It also includes and separates the many forms of household income, including Social Security benefits.

The CPS uses a rotation system for its interviews. Each housing unit is followed for a 16-month period—four months in-sample, eight months out-of-sample, and then four months in-

\footnotetext{
${ }^{4}$ Current Population Survey (2009a), page 2-1.
} 
sample. That is, a respondent in a selected housing unit is interviewed with respect to all persons living in that housing unit for four consecutive months. After eight consecutive months without being interviewed, a respondent in that housing unit is interviewed for another four consecutive months, after which the housing unit is retired from the CPS sample. In any sample month, oneeighth of the sample is being interviewed for the first time (month-in-sample, or MIS $=1$ ), oneeighth is being interviewed for the second time (MIS = 2), and so on (CPS, 2006, p. 3-13).

Because this is a housing unit-based survey rather than a person-based survey, not only can the respondent differ but some members of the household can also vary each month, and, in the extreme, all the original members of the housing unit can leave.

Because of the 4-8-4 rotation system described above, in the absence of any matching issues, a person who is in his first month-in-sample would be interviewed one year (12 months) later but would only be in his fifth month-in-sample. ${ }^{5}$ The 2009 March CPS-ASEC was administered after the 6QS was in effect, so in that dataset, everyone is asked the work-activity limitation question in March, and the 6QS at some point before, or concurrently if March is the first or fifth month-in-sample for that particular household. So, the March 2009 CPS-ASEC dataset gives us the information we need to compare these two measures of disability.

Match Process of the Restricted Use File. For this study, we matched the 2009 CPSASEC public use file to the Social Security Account Number Identification (NUMIDENT), Master Beneficiary Record (MBR), and Supplemental Security Record (SSR) files. ${ }^{6}$ The NUMIDENT file contains information on all persons who have ever submitted an application for a Social Security Number; the MBR file contains the records of the Old-Age, Survivors, and

\footnotetext{
${ }^{5}$ MIS $=2$ and MIS $=6$, MIS $=3$ and MIS $=7$, and MIS $=4$ and MIS $=8$ also create year-long matched samples.

${ }^{6}$ The matched data are available on a restricted basis to researchers with special sworn status from the Census Bureau, working on approved projects at restricted data sites, subject to the terms of an interagency agreement between the Census Bureau and SSA. All estimates were approved by SSA's Title 13 disclosure review board prior to distribution.
} 
Disability Insurance program; the SSR file contains the records of the SSI program (Davies and Fisher, 2009).

Match Rate. SSA records were matched for 90,001 of the 102,726 persons ages 25-61 in the 2009 CPS-ASEC sample-a match rate of 87.6 percent. $^{7}$ This means that 12,725 (12.5 percent of) persons ages 25-61 in the 2009 CPS-ASEC sample were not matched to SSA records. From a population perspective, using the CPS-ASEC sample weights, SSA records were matched for 131,881,301 of the 152,003,928 non-institutionalized working-age (aged 25-61) United States population-a weighted match rate of 86.8 percent.

Sample Weights. Following the recommendation of Czajka, Mabli, and Cody (2008), we rescaled our sample population using the CPS-ASEC sample weights to reestablish population representativeness of matched records across 16 age-gender subpopulations (gender by eight age groups: 25-29, 30-34, 35-39, 40-44, 45-49, 50-54, 55-59, and 60-61). ${ }^{8}$ We did so by multiplying an individual's sample weight by their rescaling factor for his/her age-gender subpopulation, where the rescaling factor is equal to the ratio of the subpopulation size of the full sample to the subpopulation size of the matched sample. ${ }^{9}$

Defining Receipt of Disability Income. Matching CPS-ASEC and SSA administrative records gives us a more precise measure of whether an individual receives Social Security income based on their disability. The receipt of SSDI income as either a Disabled Worker or as a Disabled Adult-Child (DAC) is based on whether an individual was (a) in the MBR file, (b) receiving benefits on the basis of disability (as opposed to retirement or survivorship), (c) had a

\footnotetext{
${ }^{7}$ The match rate is less than 100 percent due to several factors, including respondents not consenting to the match and the inability to determine the Social Security numbers of respondents who consented to the match.

${ }^{8}$ Czajka, Mabli, and Cody (2008) recommend that analysts rescale sample weights by demographic characteristics, as we have done.

${ }^{9}$ In the body of this paper, we only report results using our weighted matched sample. But we have also created tables using the full CPS sample. The results are similar. See Burkhauser, Fisher, Houtenville and Tennant (2012).
} 
current payment, and (d) is eligible based on his/her own contributions or the contributions of his/her retired parent(s) or deceased spouse. ${ }^{10}$ The receipt of SSI-Disabled Adult income is based on whether an individual: (a) was in the SSR file, (b) was under age 65, and (c) has a current payment.

\section{Results}

As was the case in Burkhauser et al. (forthcoming) using 2010 CPS data, when we use our 2009 matched-CPS data in Figure 2, we do not get the concentric circle model portrayed in Figure 1 . The work-activity-based disability population $(B+C)$ in the Venn diagram pictured in Figure 2 is not a subset of the 6QS-based disability population (A + B), but only partially overlaps this group. Only when the population that forms the union of these two populationsthe seven-question (7Q)-based disability population $(\mathrm{A}+\mathrm{B}+\mathrm{C})$-is considered to be the outermost circle are we able to successfully operationalize our concentric circle conceptualization of disability. However, only about 40 percent of the people in this broader disability category are the same people (that is, have positively answered both a question in the 6QS and the work-activity question-B in the diagram). Of the rest, 29 percent have answered positively to the 6QS but not the work-activity question (A), and 31 percent have responded positively to the work-activity question but not the $6 \mathrm{QS}$ (C). Hence using either the $6 \mathrm{QS}$ or the work-activity-based question alone to capture the population with disabilities will dramatically understate the population formed by using all seven questions $(\mathrm{A}+\mathrm{B}+\mathrm{C})$.

Rows 1 and 2 of Table 1 put the magnitudes of the populations in the Venn diagram into perspective. Of the 152 million Americans aged 25-61 in our weighted sample, 11.8 percent or 17.9 million have disabilities based on our 7Q-based definition $(\mathrm{A}+\mathrm{B}+\mathrm{C})$. These values fall to

\footnotetext{
${ }^{10}$ This last inclusion criterion means that individuals receiving benefits under the DAC program or the Disabled Widows/Widowers program are included, providing that the other criteria are also met.
} 
8.2 percent or 12.5 million when using solely the $6 \mathrm{QS}(\mathrm{A}+\mathrm{B})$. Hence using the $6 \mathrm{QS}$, which is the HHS-established minimum data collection standard for people with disabilities, will miss the 3.6 percent or 5.5 million working-age people who self-report having a work-activity limitation but say no to each of the six questions in the 6QS (C).

Table 1 also shows that while the overall 6QS-based disability prevalence is approximately the same as the work-activity-based disability prevalence, there are dramatic differences in these two populations’ labor force participation, employment, and poverty rates. Those in the 6QS population $(\mathrm{A}+\mathrm{B}$ ) are much more likely to be in the labor force (36.8 vs. 22.3 percent) or employed (32.0 vs. 17.8 percent) and less likely to be in poverty (24.8 vs. 28.8 percent) than those in the work-activity population $(B+C)$. But even more importantly, the 31 percent of the broader 7Q-based disability population who are in the work-activity-only disability subpopulation (C) have dramatically lower labor force (31.9 vs. 68.5) and employment (26.8 vs. 60.5) and dramatically higher poverty (26.8 vs.16.7) rates than the 29 percent who are in the 6QS-only disability subpopulation (A).

These differences in economic outcomes are accounted for to some degree in Row 6 which uses our administrative records data to show the dramatic differences in the share of those disability populations who are currently receiving SSDI income (either as a Disabled Worker or as a DAC), or SSI-Disabled Adult benefits. Part of the reason for this difference is that the severity of the impairments of those who are included in each of the various ways of creating a disability population will vary. Note that in the disability subpopulation of persons who report a 6QS-based disability and a work-activity-based disability (B), 73.4 percent are receiving disability benefits. In contrast only 21.0 percent of those in the 6QS-only subpopulation (A) and 38.4 percent of those in the work-activity-only subpopulation (C) do so. 
However, as shown below, these differences in economic outcomes are also in part accounted for by the ability of the questions used to create these various samples of the true disability population to actually capture those who administrative record data objectively tell us are receiving Social Security disability benefits.

Therefore, using either the 6QS $(\mathrm{A}+\mathrm{B})$ or work-activity $(\mathrm{B}+\mathrm{C})$ population will not only understate the larger population with disabilities captured by the seven question union of these two populations $(\mathrm{A}+\mathrm{B}+\mathrm{C})$, but it is likely to create biased estimates of the labor force, employment, and poverty rates of this broader population with disabilities in part because of these questions' different abilities to capture those currently receiving SSDI or SSI-Disabled Adults benefits.

\section{A Face Validity Test}

Prior to 2008, the American Community Survey (ACS) included the CPS-ASEC workactivity question as part of its original 6QS (See Appendix Table 1). In 2008, the ACS disability questions were substantially revised, splitting hearing and vision into separate questions and removing the work-activity question. In the matched 2009 CPS sample in Table 1, we show that this change results in 5.5 million working-age people who report having a work-activity-based disability but not a 6QS-based disability being missed by the 6QS, affecting both the overall size of the working-age population with disabilities and its measured labor force, employment, and poverty rates.

The scientific evidence for using the 6QS contained in the revised ACS was based on cognitive testing of how well respondents understood the questions and provided accurate answers. Conducted by an interagency committee using a small non-representative sample, these tests consisted of 69 interviews held over five rounds (an average of 14 interviews per round) in 
which respondents were probed as to their understanding of the questions and basis for their responses. In each round, the questions were revised to improve respondent understanding. The final results of this testing suggest that survey respondents would understand the questions in a manner sufficiently consistent with the Committee's expectations. The decision to remove the work-activity question in the ACS was made in the third round (Miller and DeMaio, 2006).

In an April 20, 2006, letter to the Census Bureau Director C. Louis Kincannon, KellerMcNulty (2006), the then-President of the American Statistical Association, urged that research on technical and methodological adjustments to a work-activity question continue so that it could be added to the ACS to improve the measurement of work disability. This advice was not followed and the work-activity question was dropped from the 6QS in the ACS in 2008. This same 6QS without a work-activity limitation question was also included in the CPS-BMS starting in June 2008. It is now the HHS "data standard for survey questions on disability.”

Below we follow Burkhauser et al. (forthcoming) and offer a face validity test of the suitability of excluding a work-activity question in a dataset that is meant to capture the population with disabilities who are targeted for government services. The Social Security Administration runs two programs that provide income to working-age people based on their disability. The SSDI program provides Disabled Worker benefits, based on their past earnings, to workers who administrators determine to be disabled—-those unable to perform substantial gainful activity because of their disability. The SSDI program also provides a DAC benefit to unmarried adults (aged 18 or older) who administrators determine to be currently disabled, based on these same SSDI disability criteria, if the disability began before age 22 and they have a parent who is deceased or is currently receiving retirement or disability benefits. It is called a child's benefit because it is paid based on the parent's Social Security earning record. The 
second program, SSI-Disabled Adult program, provides a means-tested guaranteed benefit to those who administrators determine to be disabled based on the same SSDI disability criteria.

These programs are targeted to working-age people with disabilities who are unable to earn a minimum amount of income based on an impairment stemming from their health condition. The severity of the work-activity limitation required to enter these programs is obviously within the ICF conceptualization of disability. Most importantly with respect to the representativeness of the population captured by our alternative measures of the disability population, as a class the sub-population currently receiving these benefits is less likely to be either in the labor force or employed and more likely to be in poverty. Hence one face validity test of any sequence of questions used to capture the entire disability population and its economic characteristics is its ability to capture this part of the disability population.

As was the case in Burkhauser et al. (forthcoming), when we use our 2009 matched-CPS data in Figure 3, we also do not find the concentric circle model of Figure 1. The population receiving Social Security benefits (SSDI—both Disabled Workers and DAC—and SSI-Disabled Adult) based on their responses to the 2009 matched-CPS are not a subsample of those who selfreport a work-activity limitation or even of those who report one of the 6QS-based disability questions. Instead, Figure 3 is a Venn diagram that divides the 9.5 million adults (aged 25-61) using the same self-reported disability subsets described in Figure 2. The 6QS (A + B) is able to capture 66.3 percent of this population, missing the 23.1 percent who only report a work-activity (C). Likewise, while the work-activity-based population question $(B+C)$ captures 78.0 percent of this population, it misses the 11.3 percent of Social Security beneficiaries who only report one of the six impairment/activity limitations questions (A). Together, the union of these questions 
$(A+B+C)$ captures 89.3 percent of the adult Social Security population receiving benefits based on their own disability.

Despite its greater number of questions, the $6 \mathrm{QS}$ alone is less able to identify our administrative-record-defined sample of SSDI and SSI beneficiaries than the work-activity question alone. This suggests that the failure to include some form of work-activity question in a set of questions aiming to capture the broader disability population will substantially undercount the number of persons actually receiving SSDI or SSI-Disabled Adult benefits. Because the labor force participation and employment rates of these missing beneficiaries are likely to be substantially lower than those of the rest of the working-age population with disabilities, their absence from the officially measured population with disabilities in the 6QS (A + B) is one reason for its likely upward bias in labor force participation and employment rates and its downward bias in poverty rates. What Figure 3 demonstrates is that the HHS "data standard for survey questions on disability" substantially underestimates the prevalence of SSDI and SSIDisabled Adults beneficiaries in the true disability population.

Row 1 of Table 2 repeats the percentages of the 9.5 million people in our weighted CPS data receiving SSDI and SSI-Disabled Adult benefits based on our administrative records data that are captured by each of our disability populations based on 6QS and work limitation selfreports. The next two rows of Table 2 do so for the 7.2 million who receive SSDI (either Disabled Workers or DAC) and the 3.4 million who receive SSI-Disabled Adult benefits. There is little difference in the capture rates of any of the disability populations between these two programs. $^{11}$

\footnotetext{
${ }^{11}$ The sample size for the DAC sample is too small to separate them from the recipients with previous work histories.
} 
Tables 3a and 3b take further advantage of the added information provided by the Social Security administrative records that are contained in the 2009 matched-CPS dataset. In addition to allowing us to capture the 9.5 million working-age persons who are receiving Social Security benefits based on their disability and how they are distributed across the same self-reported disability subsets described in Figure 3, it also allows us show how these distributions vary across the diagnosis groups of their primary medical condition.

We divide the data into the nine largest primary diagnosis groups and combine the rest into a tenth "other” diagnosis classification. These groups are reported from highest to lowest in terms of their populations in Table 3a and by their prevalence in Table 3b. The two largest groups_- "Mental Disorders other than intellectual disabilities” and “Musculoskeletal”_account for 4.12 million or 43.6 percent of all beneficiaries. ${ }^{12}$ The first row of Table 3a shows how the 9.5 million working-age persons receiving Social Security benefits based on their disability are distributed by how they self-report their disability. It effectively reports the total number of persons in each of the Venn diagram categories reported in Figure 3. The remaining rows show how this distribution changes across our self-reported disability populations in the CPS. The number of disability beneficiaries missed by using a 6QS is greater, the greater the size of the diagnoses group. Of the 2,240,000 with a primary diagnosis of "Mental Disorders other than intellectual disability,” 540,000 fall into the work-activity-only subpopulation (C). Hence they are missed by the 6QS. The number missed among those whose primary diagnoses is Musculoskeletal is 440,000.

The first row of Table 3b shows the percentage of the 9.5 million working-age persons receiving Social Security benefits in each of the disability subpopulations used in the Venn

\footnotetext{
${ }^{12}$ Since 15.1 percent of our diagnosis categories contain blank or invalid codes, these two largest diagnosis classifications account for 51.3 percent of all valid responses.
} 
diagram in Figure 3. The remaining rows show how these percentages change in each diagnosis group. While there is some variation by diagnosis group, in all cases but one, the work-activitybased disability population $(\mathrm{B}+\mathrm{C})$ captures a larger share than the 6QS-based disability population.

The only exception is “Nervous System and Sense Organs.” In this case 82.7 percent are captured by the 6QS population and 80.2 percent are captured in the work-activity population. Note that two of the four function-based questions in the 6QS (hearing and vision) fall within the “Nervous System and Sense Organs” diagnosis group. This may explain why the 6QS does its best job, by far, of capturing Social Security beneficiaries in this diagnosis group. It is also the only diagnosis group where that addition of the 6QS-only population (A), 13.3 percent, to the work-activity population (B + C) exceeds the addition of the work activity-only population (C), 10.8 percent, to the $6 \mathrm{QS}-$ population $(\mathrm{A}+\mathrm{B})$.

Tables 3a and 3b reinforce the point that adding the work-activity question to the 6QS would substantially increase the share of current Social Security beneficiaries—based on administrative records data—-that are captured with this broader seven-question measure of disability.

In Table 1 we observed wide variations in labor force participation, employment, and program participation rates across our disability populations. Thus including or excluding those who report a work-activity limitation only (C) importantly affected these key characteristics and hence our estimates of these key characteristics in the "true population."

Table 4 focuses on how the distribution of diagnoses varies across our disability populations based on self-reported 6QS and work-activity questions. It shows that the variation in this distribution (e.g. in Row 2, the share of "Mental Disorders other than intellectual 
disabilities” is very similar across all columns, etc.) is much less pronounced than it was for labor force participation, employment, or poverty rates in Table 1. Furthermore, the diagnoses distribution in the work-activity-only population (C) is not dramatically different from the diagnoses distribution in 6QS population (A + B) or even in the 6QS-only population (A).

The rank order of the share of conditions is quite close across all the disability populations in Table 4. In fact, the rank order of conditions in the 6QS (A+ B) perfectly matches that of the work-activity population $(B+C)$.

Even when we compare our 6QS-only (A) and work-activity-only (C) populations, the rank order is remarkably close. The only major anomaly in this comparison is that the "Nervous System and Sense Organ” diagnosis group is ranked third (10.1 percent share) in the former and sixth (4.0 percent share) in the latter. As discussed above, two of the four function-based questions in the 6QS (hearing and vision) fall within this diagnosis group. As we will discuss in more detail below, most of this difference is likely to be related to these subcategories.

Above we have argued that the 9.5 million SSDI and SSI persons in our CPS sample based on administrative records should be in any disability population. Tables 3a and 3b show that expanding to a seven-question sequence would greatly improve the ability of capturing this population in the disability population. Table 4 shows with respect to one objective measurethe share of the population captured by diagnosis category—-that there is very little difference between the distribution of such conditions in our work-activity-only population (C) and either the 6QS or the 6QS-only population. This is evidence that including the work-activity question in the 6QS would not only increase the share of those receiving Social Security benefits based on their disability but would do so without biasing the sample in this regard. 
The most difficult diagnoses to objectively measure are the two largest diagnoses categories in Table 4_-Mental Disorders other than intellectual disabilities” and "Musculoskeletal Systems."13 As can be seen in Table 4, the share of Social Security beneficiaries captured in the various self-reported disability populations not only do not vary with respect to where they fall in rank order, but are quite close in the percentage of the population they capture in each diagnosis category. Hence there is no evidence that those in the work-activity-only population even in these most difficult to diagnose categories are much different from those in the 6QS or 6QS-only populations.

\section{Each of the seven CPS question's ability to capture the Social Security disability population}

In this section we take further advantage of the added information provided by the SSA administrative records in the 2009 matched CPS dataset. In Tables 3a, 3b and 4 we disaggregated our sample of people receiving Social Security benefits based on their disability by the nine largest diagnoses groups and one "other" group containing the rest, and placed them in rows from highest to lowest population in the diagnosis group. We do so again in Table 5 but also include sub-diagnosis categories.

We are now interested in how each of the seven questions in the CPS data are able to capture these people overall and by diagnosis group. So, in this case we look not only at the six questions collectively in the 6QS category $(\mathrm{A}+\mathrm{B})$ but also individually. We compare each of the six questions' ability to capture our Social Security beneficiary population and how well they do compared to our work-activity question (B + C) in column 10 .

\footnotetext{
13 The Social Security Advisory Board (2012, p.42) found that Social Security determination policy changes in the 1980s stemming from court cases and legislation directly affected how decision makers determined eligibility for applicants who claimed to have musculoskeletal and mental impairments and since then vocational evaluations (which are only required when applicants are not granted eligibility based solely on their medical condition) are more likely to be required for cases where musculoskeletal and mental impairments are alleged.
} 
Row 1 of Table 5 reports each of the CPS question's capture value for the entire 9.5 million people represented in our CPS-linked administrative sample. The value in the first column of the first row simply repeats the value for the 6QS in the first row of Table 3b-the 6QS only captures 66.3 percent of the population. The next six columns show the ability of each of the four function-based questions and the two activity-based questions to capture this population. The next column reports the combined capture rate of these two activity-based questions. The next column reports the capture rate of the work-activity question and the final column reports the capture rate of the seven questions.

The first two function-based questions are related to hearing (7.1 percent) and vision (8.4 percent). They are the least able to capture Social Security disability beneficiaries over all. But this is primarily because deafness and blindness are relatively rare in this population. In contrast, when you look at the diagnosis row subcategory "Deafness," the hearing question captures 83.8 percent of this population. Likewise, the vision question captures 75.8 percent of the population in the diagnosis row subcategory "Visual Disturbances" and 70.9 percent in the "Blindness and Low Vision” subcategory. All these subcategory capture rates are substantially higher than the overall capture rate of 66.3 percent for all 6QS values.

A more subtle impact of these two questions can be seen by looking at the 6QS column $(\mathrm{A}+\mathrm{B})$ and comparing its capture rate with that of the work limitation question $(\mathrm{B}+\mathrm{C})$. As we saw in Table 3b, in all cases except the "Nervous System and Sense Organs” diagnosis category, the work-limitation question captured a greater share of our Social Security population.

This pattern is repeated for the nine general categories in Table 5 and it is in part because of the ability of the hearing and vision questions to disproportionately capture their primary diagnosis subcategories. But notice that in four general diagnosis categories ("Mental disorders 
other than intellectual” and "Nervous system and sense organs," "Intellectual disabilities,” and “Circulatory system”) there are sub-diagnosis categories where the 6QS outperforms the worklimitation question in capturing our Social Security beneficiary population. In virtually all those cases the "Hearing” and/or "Vision" questions are disproportionately capturing Social Security beneficiaries.

The third function-based question is related to cognitive difficulties. It captures 31.0 percent of our overall Social Security population. But this number is somewhat less impressive than it seems since it is intended to capture the largest and third largest general diagnosis categories. While it does not do as well at capturing "Mental Disorders other than intellectual disabilities" (48.4 percent) and "Intellectual Disabilities" (49.8 percent) as “Hearing” and "Vision" do in their primary subcategories, it does disproportionately capture this targeted group.

The fourth function-based question is related to physical mobility (walking and climbing stairs) and it captures the largest (43.0 percent) part of our overall Social Security disability population. Unlike the other three function-based questions, its capture rate is much more diffuse over all physical diagnoses categories with highs of 60.3 percent for the "Endocrine et al.” category and 58.9 percent for the "Musculoskeletal et al." category and its capture rates are in the 40- and 50-percent range for the rest. In contrast, its capture rates are much lower for the mental categories_-“Mental Disorders other than intellectual disabilities” (29.6 percent) and “Intellectual Disabilities” (19.1 percent).

Hence, each of these four function-based questions have capture rates that are higher for our Social Security populations whose diagnosis categories are most closely associated with the function they are trying to identify. This is evidence that each of these four function-based questions is having some success in identifying their intended populations with disabilities. 
Nevertheless collectively they only occasionally exceed the capture rate of the work-activity question.

This last point is important evidence that including a work-activity question in addition to the four function-based questions in the 6QS would substantially increase the Social Security population captured. This is much less the case with respect to the two activity-related questions that are included in the 6QS, either individually or collectively. They focus on activities of daily living (dressing or bathing) and instrumental activities of daily living (doing errands alone such as visiting a doctor's office or shopping) that require both physical and cognitive skills. But as can be seen across almost all sub-diagnosis categories, the physical mobility-function-based question captures a greater percentage of our Social Security population than either or both these activity-based questions in the diagnosis categories that are physical. Likewise, the cognitivefunction-based question captures a greater percentage of our Social Security disability population than either or both of these activity-based questions in the diagnosis categories that are mental. In two of the rare sub-diagnosis cases where this does not occur, "Visual Disturbances" and "Deafness," they are surpassed by the vision and hearing-function-based questions. It is never the case that these two activity-based questions individually or collectively outperform the workactivity question.

Table 5 suggests that for the one group that obviously should be included in any "true population" with disabilities, the four function-based questions in the 6QS do a reasonable job of capturing the part of our Social Security population whose diagnosis is most closely related to the population targeted by the question. It is far less clear how well the two activity-based questions do in this regard. Unlike the work-activity question that systematically increases the 
capture rate across almost all diagnosis subpopulations, these two questions almost never surpass the capture rate of the appropriate function-based question for these subpopulations.

\section{Reweighting Disability Samples and Possible Effects}

Our findings suggest that Keller-McNulty was right, and that a work-activity question should be added to the 6QS to better capture SSDI (Disabled Worker and DAC) and SSIDisabled Adult beneficiaries. But until this happens, at a minimum, the Census Bureau and the Department of Labor who are responsible for the development of the CPS, as well as individual researchers using these data, should consider reweighting their disability samples based on the 6QS, the work-activity question, and the union of these two ways of capturing the disability population to better capture the share of those question-based populations that are receiving SSDI and SSI benefits. They should also do so to better estimate the economic outcomes of their overall disability population.

In Table 6 we show how sensitive labor force participation, employment, and poverty rates are to two such alternative reweighting methods. Because most researchers will not have easy access to the administrative records data, in this example, we identify Social Security beneficiaries using public use self-reported information on SSDI and SSI benefit status. ${ }^{14}$

The first panel of Table 6 reports population rates for these three economic outcome variables for the 6QS-based population, the work activity-based population, and for the union of the two populations. In the next panel we show rates when we reweight beneficiaries observed in the population to adjust for those who reported receiving SSDI or SSI-Disabled Adult benefits but who are not included in the population with disabilities. Doing so assumes that these missing observations have on average the same labor force participation, employment, and poverty rates

\footnotetext{
${ }^{14}$ This exercise uses the 2009 Public Release CPS-ASEC and self-reported SSDI and SSI participation.
} 
as those we observe. In the last panel, we simply add to the disability population all missing observations who reported receiving SSDI or SSI-Disabled Adult benefits.

As a result, in all our disability populations, labor force participation and employment rates fall and poverty rates rise. But the greatest change is in the 6QS-based population since it misses the greatest share of the SSDI and SSI population.

\section{Discussion}

The Affordable Care Act of 2010 mandates the establishment of standards for the collection and dissemination of health statistics by disability status. In response, the U.S. Department of Health and Human Services recommended that the 6QS, first used in the ACS and more recently in the CPS, be the minimum data collection standard for survey questions on disability status (HHS, 2011).

However, none of these six questions directly relates to work-activity limitations. Building on Burkhauser et al. (forthcoming) we examine the consensus view as expressed in HHS (2011). In doing so, we provide further evidence that the lack of a work-activity question in the 6QS results in its inability to capture a substantial portion of the population with disabilities relevant to key U.S. disability policies and programs.

Using linked 2009 CPS-ASEC/SSA records data, we find that this 6QS captures only 66.3 percent of those actually receiving Social Security benefits based on their disability (a group that presumably should be captured as a subpopulation of any more general disability population). Furthermore, substantial portions of Social Security recipients within diagnostic groups are not captured by the 6QS.

When we add a work-activity question to the 6QS, as recommended by Burkhauser et al. (2012) based on their findings using self-reported measures of SSDI and SSI-Disabled Adult 
income receipt, we increase our Social Security disability population captured by 23.1

percentage points for a total of 89.3 percent. Hence a seven-question-sequence would capture a larger share of a subpopulation that should be in any population with disabilities—SSDI and SSIDisabled Adult beneficiaries.

Importantly, we also provide evidence that this added population is not much different with respect to its distribution of diagnoses than the 6QS or even the 6QS-only disability populations. Hence, including it with the 6QS or even the 6QS-only populations does not change the distribution of diagnoses of those captured by the larger disability population—-the one additional piece of objective information based on administrative records data we have on the characteristics of this missing piece of the disability populations captured by these questions.

This similarity with respect to the distribution of diagnoses captured is in sharp contrast to the major differences that failing to capture SSDI and SSI beneficiaries using these alternative definitions of the disability population with CPS public use data has on estimated labor force participation, employment, and poverty rates. As discussed in Table 6, a short-term way to adjust for these Type 2 errors could be reweighting the disability samples based on how well they capture SSDI/SSI-Disabled Adult recipients. These reweighting exercises provide a first approximation of the degree that current CPS-based statistics based on the 6QS and the workactivity questions overstate the labor force participation and employment rates and understate the poverty rates of working-age people with disabilities by their failure to capture all those receiving SSDI and SSI benefits in their disability definitions. 


\section{References}

Burkhauser, R. V., Fisher, T. L., Houtenville, A. J., \& Tennant, J. R. (2012) Using the 2009 CPS-ASEC-SSA Matched Dataset to Show Who Is and Is Not Captured in the Official Six-Question Sequence on Disability. University of Michigan Retirement Research Center Conference Papers. Accessed at: www.nber.org/programs/ag/rrc/rrc2012/papers/4.3\%20Burkhauser\%20Fisher\%20Houtenville.pdf.

Burkhauser, R. V., Houtenville, A. J., \& Tennant, J. R. (forthcoming). Capturing the Elusive Working-Age Population with Disabilities: Reconciling Conflicting Social Success Estimates from the Current Population Survey and the American Community Survey, Journal of Disability Policy Studies published online June 5, 2012, DOI: 10.1177/1044207312446226

Current Population Survey. 2006. Design and Methodology, Technical Paper 66. Available at: http://www.census.gov/prod/2006pubs/tp-66.pdf.

Current Population Survey. 2009a. Annual Social and Economic (ASEC) Supplement Technical Documentation. Available at: http://www.census.gov/apsd/techdoc/cps/cpsmar09.pdf.

Current Population Survey. 2009b. Frequently Asked Questions about Disability Data. Available at: http://www.bls.gov/cps/cpsdisability_faq.htm.

Czajka, J. L., Mabli, J., \& Cody, S. (2008). Sample Loss and Survey Bias in Estimates of Social Security Beneficiaries: A Tale of Two Surveys. Washington, DC: Mathematica Policy Research. Available at http://www.mathematicampr.com/publications/pdfs/samplelosssurvey.pdf.

Davies, Paul S., \& Fisher, T. Lynn. (2009). Measurement Issues Associated with Using Survey Data Matched with Administrative Data from the Social Security Administration. Social Security Bulletin. 69(2): 1-12.

HHS (U.S. Department of Health and Human Services). (2011). Implementation Guidance on Data Collection Standards for Race, Ethnicity, Sex, Primary Language, and Disability Status. Accessed at http://aspe.hhs.gov/datacncl/standards/ACA/4302/index.pdf on September 1, 2013.

Jette, A. M., \& Badley, E. (2002). Conceptual Issues in the Measurement of Work Disability. In G. S. Wunderlich, D. P. Rice, \& N. L. Amado (Eds.), The Dynamics of Disability: Measuring and Monitoring Disability for Social Security Programs (pp. 183-210). Washington DC: National Academy Press.

Keller-McNulty, S. (2006). Reference: American Community Survey and Disability. (Letter to Dr. Lewis Kincannon, Director, U.S. Census Bureau). Reproduced in AmStat News, June 2006, p. 4. 
Mathiowetz, N. A. (2002). Methodological Issues in the Measurement of Work Disability. In G. S. Wunderlich, D. P. Rice, \& N. L. Amado (Eds.), The Dynamics of Disability: Measuring and Monitoring Disability for Social Security Programs (pp. 211-240). Washington DC: National Academy Press.

Miller. K., \& T. J. DeMaio. (2006). Report of Cognitive Research on Proposed American Community Survey Disability Questions, US Census Bureau, Washington D.C.

Social Security Advisory Board. (2012) Aspects of Disability Decision Making: Data and Materials (February). Accessed at: http://ssab.gov/Publications/Disability/GPO_Chartbook_FINAL_06122012.pdf

Swanson, G., Carrothers, L., \& Mulhorn, K. (2003). Comparing Disability Survey Questions in Five Countries: A Study Using ICF to Guide Comparisons. Disability and Rehabilitation: An International Multidisciplinary Journal, 25, 665-675.

World Health Organization. (2001). International Classification of Disability, Health and Functioning. Geneva: World Health Organization. 
Figure 1. A Framework for Operationally Identifying Working-Age People with Disabilities

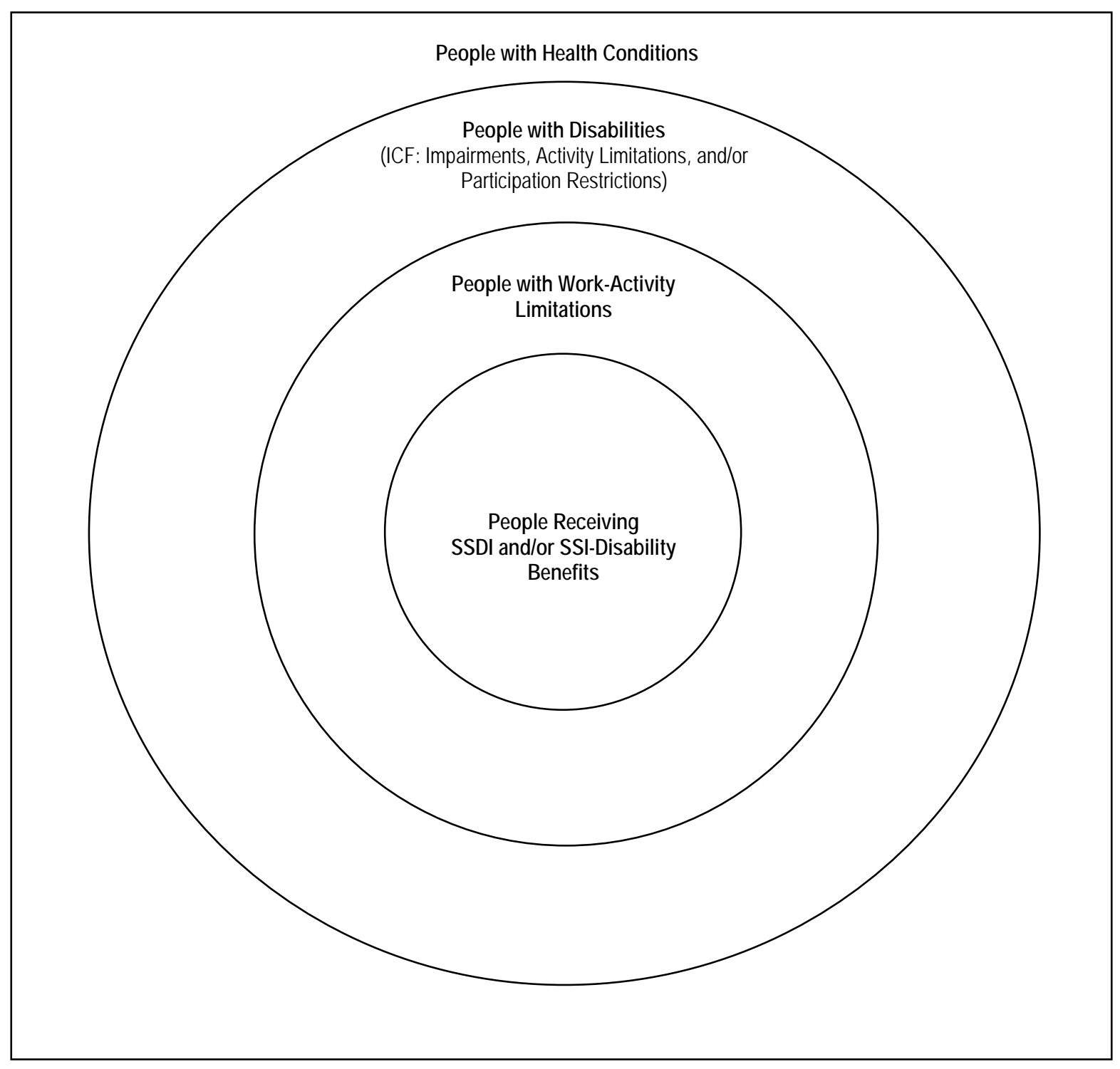


Figure 2: Prevalence rate of non-institutionalized civilians ages 25-61, by type of disability population measure, 2009 Matched SSA/CPS-ASEC

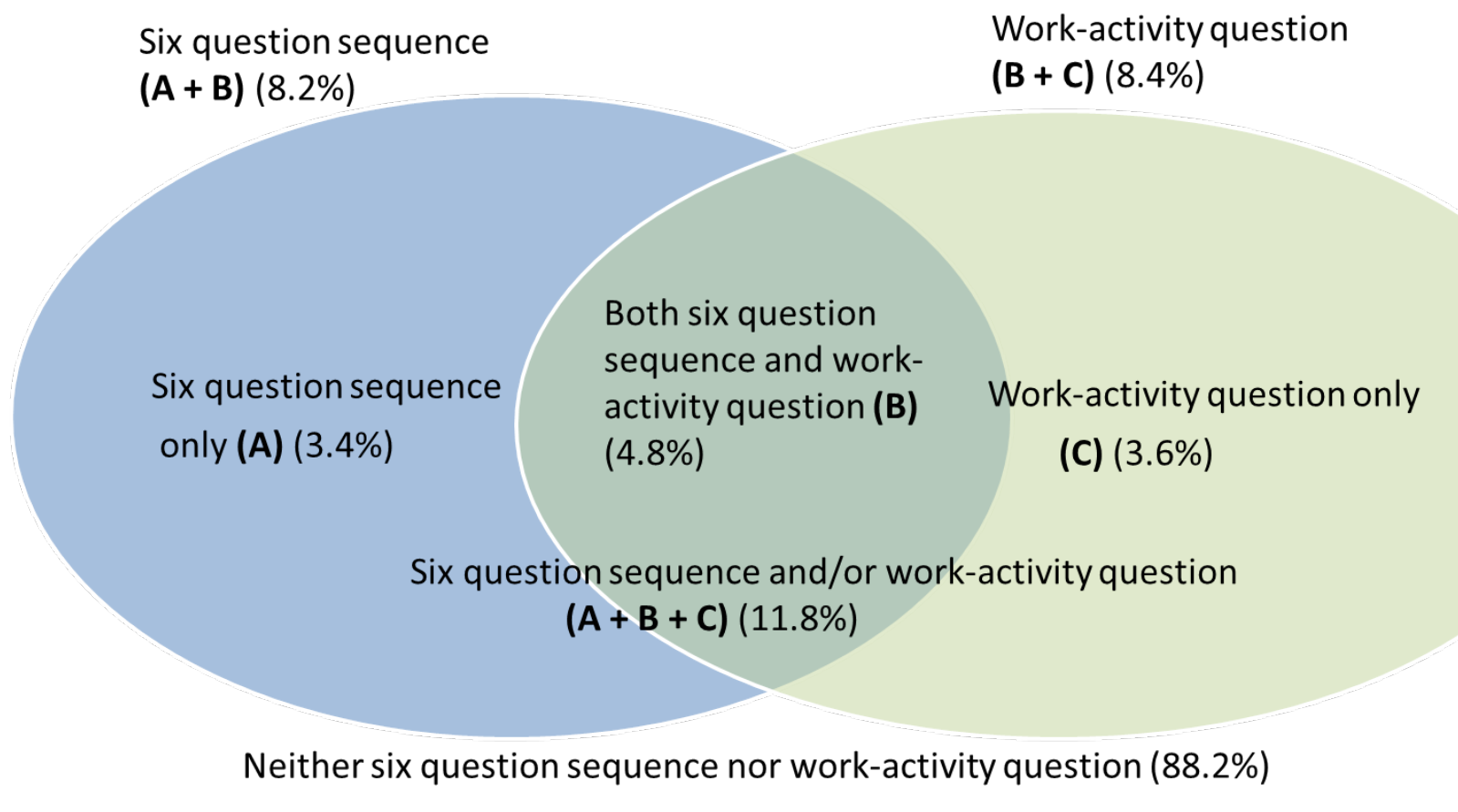


Figure 3: Percentage of Social Security program beneficiaries captured by type of disability population measure, 2009 Matched SSA/CPS-ASEC

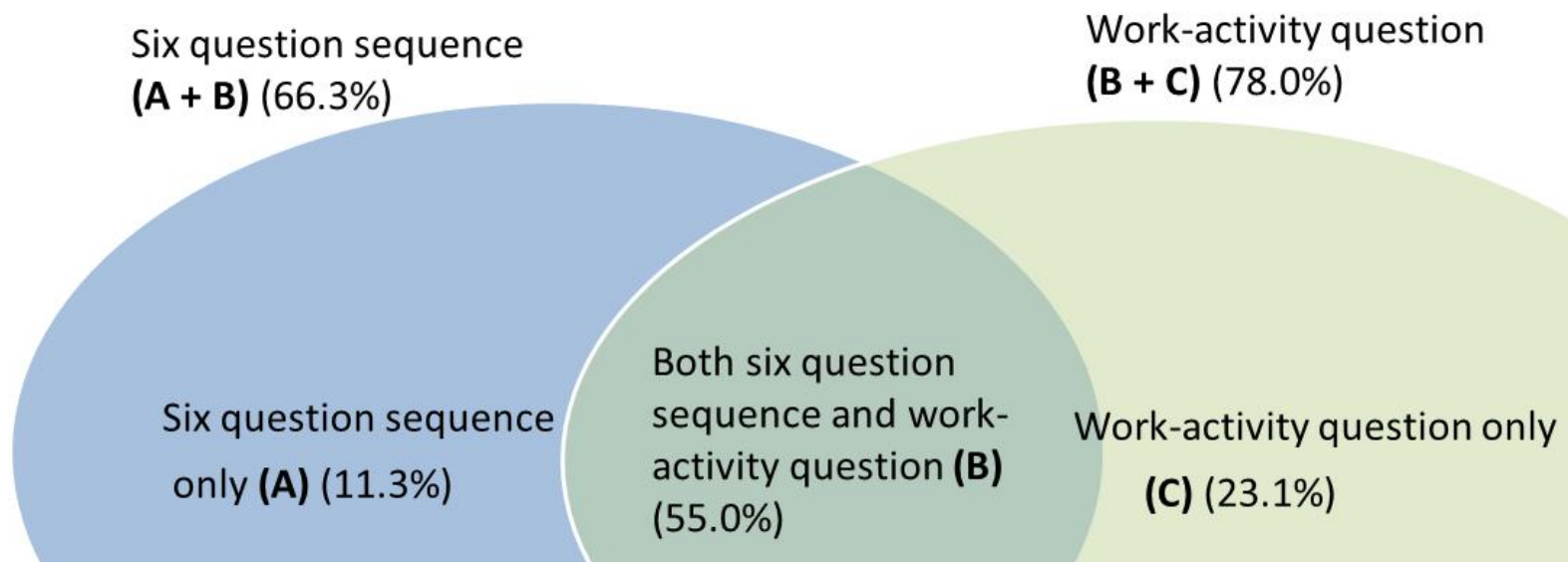

Six question sequence and/or work-activity question $(\mathbf{A}+\mathbf{B}+\mathbf{C})(89.3 \%)$

Neither six question sequence nor work-activity question (10.7\%) 
Table 1. Population size, disability prevalence rate, and economic outcomes of non-institutionalized persons ages 25-61, by type of disability population measure, using the 2009 Matched SSA/CPS-ASEC[1]

\begin{tabular}{l} 
r \\
\cline { 2 - 7 }
\end{tabular}


Table 2. Social Security program beneficiaries[1] and percentage captured by type of disability population measure, using the 2009 Matched SSA/CPS-ASEC[2]

\begin{tabular}{|c|c|c|c|c|c|c|c|c|}
\hline \multirow[b]{2}{*}{$\begin{array}{l}\text { Program } \\
\text { [1] }\end{array}$} & \multirow[b]{2}{*}{$\begin{array}{c}\text { Social } \\
\text { Security } \\
\text { population } \\
\text { size }\end{array}$} & \multicolumn{7}{|c|}{ Share captured by disability population measure } \\
\hline & & $\begin{array}{c}\text { Six } \\
\text { question } \\
\text { sequence } \\
\text { (A+B) }\end{array}$ & $\begin{array}{c}\text { Work } \\
\text { limitation } \\
(B+C)\end{array}$ & $\begin{array}{c}\text { Six } \\
\text { question } \\
\text { sequence- } \\
\text { only } \\
\text { (A) }\end{array}$ & $\begin{array}{c}\text { Both six } \\
\text { question } \\
\text { sequence } \\
\text { and work } \\
\text { limitation } \\
\text { (B) }\end{array}$ & $\begin{array}{c}\text { Work } \\
\text { activity-- } \\
\text { only } \\
\text { (C) }\end{array}$ & $\begin{array}{c}\text { Six } \\
\text { question } \\
\text { sequence } \\
\text { and/or } \\
\text { work } \\
\text { limitation } \\
(\mathrm{A}+\mathrm{B}+\mathrm{C})\end{array}$ & $\begin{array}{l}\text { Neither six } \\
\text { question } \\
\text { sequence } \\
\text { nor work } \\
\text { limitation }\end{array}$ \\
\hline DI and/or & & & & & & & & \\
\hline SSI & $9,500,000$ & 66.3 & 78.0 & 11.3 & 55.0 & 23.1 & 89.3 & 10.7 \\
\hline DI & $7,200,000$ & 66.9 & 79.2 & 10.9 & 56.0 & 23.2 & 90.1 & 9.9 \\
\hline SSI & $3,400,000$ & 65.0 & 75.2 & 12.7 & 52.3 & 22.9 & 87.9 & 12.1 \\
\hline
\end{tabular}

1. SSDI status is based on whether an individual was (a) in the MBR file, (b) receiving benefits on the basis of disability (as opposed to retirement or survivorship), and (c) had a current payment. SSI status is based on whether an individual was (a) in the SSR file, (b) under age 65, and (c) has a current payment.

2. The 2009 CPS-ASEC file was matched to the SSA Numident file. Numident records were matched for 90,001 of the 102,726 non-institutionalized persons ages 25-61 in the 2009 CPS-ASEC sample-a match rate of 87.6 percent. Hence 12,725 or 12.5 percent of non-institutionalized persons ages 25-61 in the 2009 CPS-ASEC sample were not matched to Numident records. The CPS-ASEC sample weight was rescaled based on gender and age to account for nonmatching sample and reestablish population size estimates. 
Table 3a. Social Security program beneficiaries[1] by diagnosis group and the number captured by type of disability population measure using the 2009 Matched SSA/CPS-ASEC[2]

\begin{tabular}{|c|c|c|c|c|c|c|c|c|}
\hline \multirow[b]{2}{*}{ Diagnosis group } & & \multicolumn{7}{|c|}{ Number captured by disability population measure } \\
\hline & $\begin{array}{c}\text { Social } \\
\text { Security } \\
\text { total }\end{array}$ & $\begin{array}{c}\text { Six } \\
\text { question } \\
\text { sequence } \\
(\mathbf{A}+\mathbf{B})\end{array}$ & $\begin{array}{c}\text { Work } \\
\text { limitation } \\
(B+C)\end{array}$ & $\begin{array}{c}\text { Six } \\
\text { question } \\
\text { sequence- } \\
\text { only } \\
\text { (A) }\end{array}$ & $\begin{array}{c}\text { Both six } \\
\text { question } \\
\text { sequence } \\
\text { and work } \\
\text { limitation } \\
\text { (B) }\end{array}$ & $\begin{array}{c}\text { Work } \\
\text { activity- } \\
\text { only } \\
\text { (C) }\end{array}$ & $\begin{array}{c}\text { Six } \\
\text { question } \\
\text { sequence } \\
\text { and/or } \\
\text { work } \\
\text { limitation } \\
(\mathrm{A}+\mathrm{B}+\mathrm{C})\end{array}$ & $\begin{array}{c}\text { Neither } \\
\text { six } \\
\text { question } \\
\text { sequence } \\
\text { nor work } \\
\text { limitation }\end{array}$ \\
\hline All groups & $9,500,000$ & $6,280,000$ & $7,390,000$ & $1,070,000$ & $5,210,000$ & $2,190,000$ & $8,460,000$ & $1,010,000$ \\
\hline $\begin{array}{l}\text { Mental disorders other than } \\
\text { intellectual disability }\end{array}$ & $2,240,000$ & $1,500,000$ & $1,800,000$ & 260,000 & $1,200,000$ & 540,000 & $2,000,000$ & 230,000 \\
\hline Musculoskeletal system & $1,880,000$ & $1,200,000$ & $1,500,000$ & 200,000 & $1,000,000$ & 440,000 & $1,700,000$ & 200,000 \\
\hline Nervous system and sense organs & 810,000 & 670,000 & 650,000 & 110,000 & 560,000 & 90,000 & 760,000 & 50,000 \\
\hline Intellectual disability & 770,000 & 490,000 & 590,000 & 90,000 & 400,000 & 190,000 & 680,000 & 90,000 \\
\hline Circulatory system & 620,000 & 400,000 & 480,000 & 70,000 & 330,000 & 150,000 & 550,000 & 70,000 \\
\hline Injuries & 380,000 & 250,000 & 310,000 & 40,000 & 210,000 & 100,000 & 350,000 & 30,000 \\
\hline Endocrine, nutritional, metabolic & 300,000 & 200,000 & 250,000 & 20,000 & 180,000 & 70,000 & 280,000 & 30,000 \\
\hline Respiratory system & 200,000 & 120,000 & 170,000 & 20,000 & 100,000 & 70,000 & 190,000 & 10,000 \\
\hline Neoplasms & 190,000 & 90,000 & 140,000 & 20,000 & 80,000 & 60,000 & 150,000 & 40,000 \\
\hline Other & 640,000 & 420,000 & 480,000 & 72,000 & 350,000 & 143,000 & 560,000 & 83,000 \\
\hline Blank/invalid code & $1,430,000$ & 900,000 & $1,100,000$ & 170,000 & 740,000 & 340,000 & $1,200,000$ & 180,000 \\
\hline
\end{tabular}

1. SSDI status is based on whether an individual was (a) in the MBR file, (b) receiving benefits on the basis of disability (as opposed to retirement or survivorship), and (c) had a current payment. SSI status is based on whether an individual was (a) in the SSR file, (b) under age 65, and (c) has a current payment.

2. The 2009 CPS-ASEC file was matched to the SSA Numident file. Numident records were matched for 90,001 of the 102,726 non-institutionalized persons ages 25-61 in the 2009 CPS-ASEC sample-a match rate of 87.6 percent. Hence 12,725 or 12.5 percent of non-institutionalized persons ages $25-61$ in the 2009 CPS-ASEC sample were not matched to Numident records. The CPS-ASEC sample weight was rescaled based on gender and age to account for non-matching sample and reestablish population size estimates. 
Table 3b. Social Security program beneficiaries[1] and the percent captured, by diagnosis group and type of disability population measure using the 2009 Matched SSA/CPS-ASEC[2]

\begin{tabular}{|c|c|c|c|c|c|c|c|c|}
\hline \multirow[b]{2}{*}{ Diagnosis group } & \multirow[b]{2}{*}{$\begin{array}{c}\text { Social } \\
\text { Security } \\
\text { total }\end{array}$} & \multicolumn{7}{|c|}{ Disability population measure } \\
\hline & & $\begin{array}{c}\text { Six } \\
\text { question } \\
\text { sequence } \\
\text { (A+B) }\end{array}$ & $\begin{array}{c}\text { Work } \\
\text { limitation } \\
(B+C)\end{array}$ & $\begin{array}{c}\text { Six } \\
\text { question } \\
\text { sequence- } \\
\text { only } \\
\text { (A) }\end{array}$ & $\begin{array}{l}\text { Both six } \\
\text { question } \\
\text { sequence } \\
\text { and work } \\
\text { limitation } \\
\text { (B) }\end{array}$ & $\begin{array}{l}\text { Work } \\
\text { activity- } \\
\text { only } \\
\text { (C) }\end{array}$ & $\begin{array}{c}\text { Six } \\
\text { question } \\
\text { sequence } \\
\text { and/or } \\
\text { work } \\
\text { limitation } \\
(\mathrm{A}+\mathrm{B}+\mathrm{C})\end{array}$ & $\begin{array}{l}\text { Neither } \\
\text { six } \\
\text { question } \\
\text { sequence } \\
\text { nor work } \\
\text { limitation }\end{array}$ \\
\hline All groups & $9,500,000$ & 66.3 & 78.0 & 11.3 & 55.0 & 23.1 & 89.3 & 10.7 \\
\hline $\begin{array}{l}\text { Mental disorders other than } \\
\text { intellectual disability }\end{array}$ & $2,240,000$ & 65.9 & 78.2 & 11.6 & 54.4 & 23.9 & 89.8 & 10.2 \\
\hline Musculoskeletal system & $1,880,000$ & 66.1 & 78.6 & 10.8 & 55.3 & 23.3 & 89.4 & 10.6 \\
\hline Nervous system and sense organs & 810,000 & 82.7 & 80.2 & 13.3 & 69.4 & 10.8 & 93.5 & 6.5 \\
\hline Intellectual disability & 770,000 & 64.5 & 76.9 & 11.8 & 52.6 & 24.3 & 88.8 & 11.2 \\
\hline Circulatory system & 620,000 & 64.6 & 77.2 & 11.3 & 53.4 & 23.8 & 88.5 & 11.5 \\
\hline Injuries & 380,000 & 66.6 & 82.3 & 10.3 & 56.3 & 26.0 & 92.6 & 7.4 \\
\hline Endocrine, nutritional, metabolic & 300,000 & 66.6 & 83.0 & 8.1 & 58.5 & 24.6 & 91.1 & 8.9 \\
\hline Respiratory system & 200,000 & 57.8 & 83.7 & 9.6 & 48.3 & 35.5 & 93.3 & 6.7 \\
\hline Neoplasms & 190,000 & 49.1 & 70.9 & 7.9 & 41.2 & 29.6 & 78.7 & 21.3 \\
\hline Other & 640,000 & 65.5 & 76.0 & 11.5 & 53.9 & 23.2 & 87.2 & 12.8 \\
\hline Blank/invalid code & $1,430,000$ & 63.4 & 75.4 & 11.7 & 51.6 & 23.8 & 87.2 & 12.8 \\
\hline
\end{tabular}

1. SSDI status is based on whether an individual was (a) in the MBR file, (b) receiving benefits on the basis of disability (as opposed to retirement or survivorship), and (c) had a current payment. SSI status is based on whether an individual was (a) in the SSR file, (b) under age 65, and (c) has a current payment.

2. The 2009 CPS-ASEC file was matched to the SSA Numident file. Numident records were matched for 90,001 of the 102,726 non-institutionalized persons ages 25-61 in the 2009 CPS-ASEC sample-a match rate of 87.6 percent. Hence 12,725 or 12.5 percent of persons ages 25-61 in the 2009 CPS-ASEC sample were not matched to Numident records. The CPS-ASEC sample weight was rescaled based on gender and age to account for non-matching sample and reestablish population size estimates. 
Table 4. Percentage of Social Security program beneficiaries[1] by diagnosis group and type of disability population measure using the 2009 Matched SSA/CPS-ASEC[2]

\begin{tabular}{|c|c|c|c|c|c|c|c|c|}
\hline \multirow[b]{2}{*}{ Diagnosis group } & \multirow[b]{2}{*}{$\begin{array}{c}\text { Social } \\
\text { Security } \\
\text { total }\end{array}$} & \multicolumn{7}{|c|}{ Disability population measure } \\
\hline & & $\begin{array}{c}\text { Six } \\
\text { question } \\
\text { sequence } \\
\text { (A+B) }\end{array}$ & $\begin{array}{c}\text { Work } \\
\text { limitation } \\
(B+C)\end{array}$ & $\begin{array}{c}\text { Six } \\
\text { question } \\
\text { sequence- } \\
\text { only } \\
\text { (A) }\end{array}$ & $\begin{array}{c}\text { Both six } \\
\text { question } \\
\text { sequence } \\
\text { and work } \\
\text { limitation } \\
\text { (B) }\end{array}$ & $\begin{array}{c}\text { Work } \\
\text { activity- } \\
\text { only } \\
\text { (C) }\end{array}$ & $\begin{array}{c}\text { Six } \\
\text { question } \\
\text { sequence } \\
\text { and/or } \\
\text { work } \\
\text { limitation } \\
(\mathrm{A}+\mathrm{B}+\mathrm{C})\end{array}$ & $\begin{array}{l}\text { Neither } \\
\text { six } \\
\text { question } \\
\text { sequence } \\
\text { nor work } \\
\text { limitation }\end{array}$ \\
\hline Musculoskeletal system & 19.9 & 19.8 & 20.0 & 19.0 & 20.0 & 20.0 & 19.9 & 19.7 \\
\hline Nervous system and sense organs & 8.6 & 10.7 & 8.8 & 10.1 & 10.8 & 4.0 & 9.0 & 5.2 \\
\hline Intellectual disability & 8.1 & 7.9 & 8.0 & 8.5 & 7.7 & 8.5 & 8.0 & 8.5 \\
\hline Circulatory system & 6.6 & 6.4 & 6.5 & 6.6 & 6.4 & 6.8 & 6.5 & 7.1 \\
\hline Other & 6.6 & 6.7 & 6.6 & 6.7 & 6.7 & 6.9 & 6.5 & 8.1 \\
\hline Blank/invalid code & 15.1 & 14.4 & 14.6 & 15.6 & 14.1 & 15.5 & 14.7 & 18.0 \\
\hline
\end{tabular}

1. SSDI status is based on whether an individual was (a) in the MBR file, (b) receiving benefits on the basis of disability (as opposed to retirement or survivorship), and (c) had a current payment. SSI status is based on whether an individual was (a) in the SSR file, (b) under age 65, and (c) has a current payment.

2. The 2009 CPS-ASEC file was matched to the SSA Numident file. Numident records were matched for 90,001 of the 102,726 non-institutionalized persons ages 2561 in the 2009 CPS-ASEC sample-a match rate of 87.6 percent. Hence 12,725 or 12.5 percent of persons ages 25-61 in the 2009 CPS-ASEC sample were not matched to Numident records. The CPS-ASEC sample weight was rescaled based on gender and age to account for non-matching sample and reestablish population size estimates. 
Table 5. Percentage of Social Security program beneficiaries[1] captured, by diagnosis group and type of disability population measure using the 2009 Matched SSA/CPS-ASEC[2]

\begin{tabular}{|c|c|c|c|c|c|c|c|c|c|c|}
\hline \multirow[b]{2}{*}{ Diagnosis group/select diagnosis (diagnosis code(s)) } & \multicolumn{10}{|c|}{ Disability population measure } \\
\hline & $\begin{array}{c}\text { Six } \\
\text { question } \\
\text { Sequence }\end{array}$ & Hearing & Vision & Cognitive & Ambulatory & $\begin{array}{l}\text { Self- } \\
\text { care }\end{array}$ & $\begin{array}{c}\text { Ind. } \\
\text { Living }\end{array}$ & $\begin{array}{l}\text { Self- } \\
\text { care } \\
\text { and/or } \\
\text { Ind. } \\
\text { Living. }\end{array}$ & $\begin{array}{c}\text { Work } \\
\text { activity }\end{array}$ & $\begin{array}{c}\text { Seven } \\
\text { question } \\
\text { sequence }\end{array}$ \\
\hline All groups & 66.3 & 7.1 & 8.4 & 31.0 & 43.0 & 15.8 & 31.5 & 34.6 & 78.0 & 89.3 \\
\hline Mental diagnoses other than mental retardation $(290-315.2,315.3-316)$ & 65.9 & 6.9 & 6.1 & 48.4 & 29.6 & 11.4 & 31.2 & 33.2 & 78.2 & 89.8 \\
\hline Other organic psychotic conditions (chronic) (all 294) & 72.2 & 11.1 & 7.7 & 56.3 & 35.2 & 11.2 & 28.4 & 30.3 & 71.1 & 93.5 \\
\hline Schizophrenic disorders (all 295) & 64.9 & 4.0 & 6.3 & 55.5 & 16.8 & 12.1 & 31.0 & 32.7 & 76.7 & 88.7 \\
\hline Episodic mood disorders (all 296) & 64.4 & 6.5 & 5.7 & 44.3 & 31.8 & 10.4 & 29.0 & 31.3 & 81.4 & 89.4 \\
\hline Neurotic disorders (all 300) & 64.7 & 5.2 & 1.8 & 45.7 & 29.9 & 8.5 & 37.7 & 37.9 & 79.6 & 91.8 \\
\hline Personality disorders (all 301) & 73.4 & 16.5 & 15.8 & 41.6 & 48.7 & 33.2 & 43.2 & 51.8 & 60.3 & 82.7 \\
\hline Physiological malfunction arising from mental factors (306) & 77.9 & 29.3 & 15.9 & 46.8 & 63.8 & 15.9 & 48.3 & 48.3 & 47.6 & 77.9 \\
\hline Diseases of the musculoskeletal system and connective tissue (710-739) & 66.1 & 7.2 & 4.0 & 17.2 & 58.9 & 16.4 & 23.5 & 28.1 & 78.6 & 89.4 \\
\hline Diffuse diseases of connective tissue (710) & 76.3 & 8.7 & 5.1 & 41.5 & 65.4 & 7.9 & 23.4 & 30.2 & 82.8 & 95.4 \\
\hline Rheumatoid arthritis and other imflammatory polyarthropathies (714) & 75.1 & 2.2 & 4.1 & 15.1 & 69.8 & 38.0 & 31.0 & 48.0 & 83.4 & 93.1 \\
\hline Osteoarthritis and allied disorders (715) & 74.1 & 8.6 & 5.5 & 20.1 & 67.7 & 17.7 & 30.6 & 32.9 & 81.1 & 92.9 \\
\hline Other and unspecified arthropathies (716) & 58.5 & 5.0 & 3.3 & 13.4 & 52.1 & 10.2 & 8.8 & 12.7 & 62.0 & 68.8 \\
\hline Other and unspecified disorders of back (all 724) & 64.7 & 7.7 & 4.1 & 16.3 & 57.1 & 14.7 & 22.6 & 26.3 & 77.4 & 88.4 \\
\hline Disorders of muscle, ligament, and fascia (728) & 50.3 & 5.7 & 1.2 & 16.0 & 45.1 & 11.7 & 10.1 & 15.7 & 84.3 & 89.4 \\
\hline Other disorders of bone and cartilage (733) & 50.6 & 3.3 & 0.0 & 22.1 & 45.0 & 37.1 & 34.1 & 44.9 & 95.6 & 100.0 \\
\hline Diseases of the nervous system and sense organs (320-389) & 82.7 & 12.5 & 23.9 & 22.7 & 54.4 & 28.6 & 43.7 & 48.2 & 80.2 & 93.5 \\
\hline Other cerebral degenerations (331) & 89.7 & 0.0 & 13.0 & 54.0 & 81.8 & 38.6 & 67.4 & 68.7 & 71.6 & 100.0 \\
\hline $\begin{array}{l}\text { Other diseases of spinal cord (incl. syringomyelia and syringobulbia) } \\
\text { (336) }\end{array}$ & 84.1 & 9.9 & 0.0 & 12.8 & 84.1 & 69.4 & 61.8 & 70.9 & 80.0 & 84.1 \\
\hline Multiple sclerosis $(340)$ & 89.0 & 0.3 & 17.2 & 37.1 & 74.9 & 41.7 & 59.3 & 61.5 & 85.9 & 96.4 \\
\hline Infantile cerebral palsy (all 343) & 85.8 & 4.6 & 11.0 & 30.2 & 74.3 & 43.1 & 53.3 & 56.2 & 71.4 & 95.8 \\
\hline
\end{tabular}




\begin{tabular}{|c|c|c|c|c|c|c|c|c|c|c|}
\hline Epilepsy (345) & 64.4 & 6.2 & 4.2 & 37.3 & 25.2 & 24.4 & 38.6 & 41.2 & 88.7 & 93.9 \\
\hline Migraine (346) & 51.6 & 3.6 & 22.0 & 36.5 & 33.3 & 0.0 & 18.2 & 18.2 & 94.6 & 94.6 \\
\hline Other and unspecified disorders of the nervous system (349) & 74.9 & 1.2 & 4.5 & 24.6 & 66.4 & 28.4 & 41.6 & 48.2 & 91.3 & 91.9 \\
\hline Inflammatory and toxic neuropathy (all 357) & 92.6 & 7.2 & 21.6 & 11.0 & 79.6 & 34.7 & 54.5 & 67.7 & 87.7 & 96.7 \\
\hline Muscular dystrophies and other myopathies (359) & 94.8 & 9.0 & 4.8 & 39.3 & 73.5 & 53.3 & 28.9 & 53.3 & 90.5 & 100.0 \\
\hline Visual disturbances (368) & 81.2 & 9.9 & 75.8 & 0.0 & 5.3 & 0.0 & 50.7 & 50.7 & 74.6 & 93.6 \\
\hline Blindness and low vision (369) & 78.9 & 7.6 & 70.9 & 12.3 & 24.7 & 12.1 & 35.4 & 35.4 & 82.3 & 91.8 \\
\hline Deafness (all 389) & 87.0 & 83.8 & 9.3 & 6.8 & 8.4 & 0.0 & 8.7 & 8.7 & 66.0 & 87.0 \\
\hline Intellectual disabilities (317-319.5, 319.6-320) & 64.5 & 6.5 & 6.0 & 49.8 & 19.1 & 13.3 & 41.0 & 41.2 & 76.9 & 88.8 \\
\hline Mild intellectual disability (317) & 47.1 & 0.0 & 0.0 & 37.8 & 9.3 & 1.3 & 19.6 & 19.6 & 66.4 & 74.4 \\
\hline Other specified intellectual disability (all 318) & 65.0 & 6.4 & 6.2 & 50.3 & 19.4 & 13.6 & 41.7 & 41.9 & 77.0 & 89.0 \\
\hline Unspecified intellectual disability (319.5) & 78.9 & 1.7 & 5.6 & 62.8 & 33.7 & 2.3 & 37.5 & 37.5 & 73.2 & 92.7 \\
\hline Circulatory system (390-459) & 64.6 & 5.1 & 10.1 & 21.5 & 51.6 & 15.6 & 31.2 & 33.3 & 77.2 & 88.5 \\
\hline Essential hypertension (401) & 80.5 & 22.9 & 16.8 & 27.8 & 65.1 & 20.8 & 42.9 & 42.9 & 65.0 & 90.6 \\
\hline Other forms of chronic ischemic heart disease (414) & 61.1 & 2.8 & 7.4 & 19.9 & 43.7 & 10.2 & 25.4 & 27.1 & 70.7 & 87.8 \\
\hline Cardiomyopathy (425) & 55.7 & 1.9 & 18.1 & 29.6 & 45.6 & 9.9 & 29.7 & 36.2 & 92.9 & 96.1 \\
\hline Heart failure (428) & 38.0 & 0.0 & 3.1 & 10.3 & 34.4 & 11.5 & 28.7 & 30.4 & 82.3 & 89.0 \\
\hline Late effects of cerebrovascular disease (438) & 72.5 & 8.3 & 7.1 & 29.6 & 60.2 & 27.9 & 41.7 & 44.4 & 77.7 & 87.9 \\
\hline Other peripheral vascular disease (443) & 82.3 & 0.0 & 2.0 & 14.5 & 75.1 & 21.1 & 36.6 & 40.7 & 96.4 & 96.8 \\
\hline Hemorrhoids (454) & 45.7 & 0.0 & 0.0 & 0.0 & 45.7 & 0.0 & 25.1 & 25.1 & 71.1 & 71.1 \\
\hline Other disorders of circulatory system (459) & 53.7 & 1.9 & 10.1 & 0.0 & 53.7 & 7.9 & 20.6 & 20.6 & 56.5 & 76.2 \\
\hline Injury and poisoning (800-999) & 66.6 & 3.2 & 7.6 & 18.0 & 57.2 & 32.6 & 31.5 & 42.1 & 82.3 & 92.6 \\
\hline Fracture of vertebral column with spinal cord injury (806) & 76.2 & 0.0 & 0.0 & 8.7 & 76.2 & 55.6 & 48.7 & 58.6 & 96.9 & 97.5 \\
\hline III-defined fractures of upper limb (818) & 36.1 & 3.2 & 12.1 & 26.5 & 32.0 & 16.3 & 6.9 & 23.2 & 74.2 & 77.2 \\
\hline Other, multiple, and ill-defined fractures of lower limb (827) & 66.6 & 3.4 & 12.6 & 20.2 & 55.4 & 25.7 & 19.7 & 34.6 & 88.9 & 97.1 \\
\hline Intracranial injury of other and unspecified nature (854) & 56.8 & 8.5 & 17.3 & 26.2 & 32.3 & 26.8 & 24.0 & 26.8 & 79.1 & 89.5 \\
\hline Late effects of musculoskeletal and connective tissue injuries (905) & 65.3 & 9.5 & 0.0 & 18.8 & 48.7 & 21.2 & 27.3 & 31.0 & 78.9 & 94.7 \\
\hline Late effects of injuries to the nervous system (907) & 66.4 & 0.0 & 12.6 & 23.6 & 61.9 & 34.9 & 52.7 & 57.8 & 80.3 & 88.6 \\
\hline
\end{tabular}




\begin{tabular}{|c|c|c|c|c|c|c|c|c|c|c|}
\hline $\begin{array}{l}\text { Endocrine, nutritional/metabolic diseases, and immunity disorders } \\
(240-248,249-279)\end{array}$ & 66.6 & 6.1 & 13.0 & 20.1 & 60.3 & 16.2 & 34.3 & 37.3 & 83.0 & 91.1 \\
\hline Other $(248)$ & 68.9 & 12.0 & 4.4 & 23.6 & 55.1 & 21.0 & 36.7 & 39.4 & 78.2 & 90.0 \\
\hline Diabetes mellitus (all 250) & 68.6 & 7.6 & 19.4 & 20.8 & 62.2 & 13.3 & 38.3 & 39.0 & 80.8 & 89.1 \\
\hline Obesity and other hyperalimentation (278) & 68.0 & 5.9 & 8.1 & 21.1 & 61.9 & 22.2 & 35.1 & 40.9 & 83.5 & 93.1 \\
\hline Respiratory system (460-519) & 57.8 & 5.7 & 6.7 & 14.1 & 48.6 & 13.1 & 29.4 & 31.9 & 83.7 & 93.3 \\
\hline Emphysema (492) & 83.6 & 1.2 & 0.0 & 7.0 & 76.4 & 25.1 & 45.0 & 45.0 & 100.0 & 100.0 \\
\hline Asthma (493) & 52.5 & 2.8 & 9.9 & 17.7 & 49.5 & 13.7 & 24.5 & 24.5 & 72.2 & 84.7 \\
\hline Chronic airway obstruction, NOS (incl. COPD, NOS) (496) & 50.3 & 8.9 & 7.1 & 14.1 & 37.6 & 8.6 & 23.2 & 27.7 & 87.5 & 95.6 \\
\hline Neoplasms (140-239) & 49.1 & 2.2 & 4.6 & 16.4 & 39.5 & 9.8 & 22.9 & 24.5 & 70.9 & 78.7 \\
\hline Malignant neoplasm of trachea, bronchus, and lung (162) & 53.4 & 0.0 & 0.0 & 14.1 & 39.3 & 0.0 & 1.1 & 1.1 & 74.7 & 86.7 \\
\hline Malignant neoplasm of female breast (174) & 46.8 & 0.0 & 5.0 & 12.5 & 27.9 & 2.7 & 20.0 & 22.7 & 83.2 & 88.2 \\
\hline
\end{tabular}

1. SSDI status is based on whether an individual was (a) in the MBR file, (b) receiving benefits on the basis of disability (as opposed to retirement or survivorship), and (c) had a current payment. SSI status is based on whether an individual was (a) in the SSR file, (b) under age 65, and (c) has a current payment.

2. The 2009 CPS-ASEC file was matched to the SSA Numident file. Numident records were matched for 90,001 of the 102,726 non-institutionalized persons ages 2561 in the 2009 CPS-ASEC sample-a match rate of 87.6 percent. Hence 12,725 or 12.5 percent of persons ages 25-61 in the 2009 CPS-ASEC sample were not matched to Numident records. The CPS-ASEC sample weight was rescaled based on gender and age to account for non-matching sample and reestablish population size estimates. 
Table 6. Economic outcomes of non-institutionalized persons ages 25-61 under the assumption that each disability population measure type captured all SSDI and SSI participants using two methods[1,2], by disability measure, using the 2009 Public Release CPS-ASEC

\begin{tabular}{|c|c|c|c|}
\hline \multirow[b]{2}{*}{ Economic variable } & \multicolumn{3}{|c|}{ Disability population measure } \\
\hline & $\begin{array}{c}\text { Six question } \\
\text { sequence } \\
(\mathbf{A}+\mathbf{B})\end{array}$ & $\begin{array}{l}\text { Work limitation } \\
\qquad(\mathrm{B}+\mathrm{C})\end{array}$ & $\begin{array}{c}\text { Seven } \\
\text { question } \\
\text { sequence } \\
(\mathrm{A}+\mathrm{B}+\mathrm{C})\end{array}$ \\
\hline Employment rate & 31.1 & 17.3 & 29.0 \\
\hline Labor force participation rate & 35.9 & 21.3 & 34.2 \\
\hline \multirow[t]{2}{*}{ Poverty rate } & 25.9 & 29.2 & 26.2 \\
\hline & \multicolumn{3}{|c|}{$\begin{array}{c}\text { Method 1: Reweighting Identified SSDI and SSI } \\
\text { participants to reflect total participants }\end{array}$} \\
\hline Employment rate & 26.8 & 16.3 & 28.3 \\
\hline Labor force participation rate & 30.8 & 20.1 & 33.4 \\
\hline \multirow[t]{2}{*}{ Poverty rate } & 26.7 & 29.4 & 26.3 \\
\hline & \multicolumn{3}{|c|}{$\begin{array}{c}\text { Method 2: Adding in missed SSDI and SSI } \\
\text { participants }\end{array}$} \\
\hline Employment rate & 27.3 & 17.0 & 28.7 \\
\hline Labor force participation rate & 31.6 & 20.8 & 33.8 \\
\hline Poverty rate & 27.0 & 29.6 & 26.5 \\
\hline
\end{tabular}

1. SSDI participation is based on responses to the following question: Did (you/name) receive Social Security? [If yes] what were the reasons (you/name) (was/were) getting Social Security income last year? [retired; disabled (adult or child); widowed; spouse; surviving child; dependent child; on behalf of surviving, dependent, or disabled child(ren); other (adult or child). Respondents were allowed two reasons. SSI participation is based on responses to the following question: Did (you/name) receive SSI? [If yes] what were the reasons (you/name) (was/were) getting Supplemental Security Income last year? [disabled (adult or child); blind (adult or child); on behalf of a disabled child; on behalf of a blind child; other (adult or child)]. Respondents were allowed two reasons.

2. We utilize two approaches: (a) reweight beneficiaries observed in each disability population to reflect the total number of beneficiaries and (b) add in the missing beneficiaries into the disability populations identified by each measure. Both will yield the same population and prevalence rates, however their employment rates will differ because the reweighting approach assumes the employment rate of the observed beneficiaries in the disability population is the same as the employment rate of the missed beneficiaries The "add in" approach does not need to make such an assumption because the employment of the missed beneficiaries is known and used. 


\section{Appendix Table 1. Disability, employment, and program participation questions in the Current Population Survey}

\begin{tabular}{|c|c|}
\hline Question (Survey) & Question wording \\
\hline \multicolumn{2}{|l|}{ Disability question } \\
\hline \multirow{2}{*}{$\begin{array}{l}\text { Hearing difficulty (CPS-BMS) } \\
\text { Vision difficulty (CPS-BMS) }\end{array}$} & Is anyone deaf or does anyone have serious difficulty hearing? \\
\hline & Is anyone blind or does anyone have serious difficulty seeing even when wearing glasses? \\
\hline \multirow[b]{2}{*}{ Physical difficulty (CPS-BMS) } & $\begin{array}{l}\text { Because of a physical, mental, or emotional condition, does anyone have serious difficulty concentrating, remembering or } \\
\text { making decisions? }\end{array}$ \\
\hline & Does anyone have serious difficulty walking or climbing stairs? \\
\hline Self-care difficulty (CPS-BMS) & Does anyone have difficulty dressing or bathing? \\
\hline $\begin{array}{l}\text { Independent living difficulty } \\
\text { (CPS-BMS) }\end{array}$ & $\begin{array}{l}\text { Because of a physical, mental or emotional condition, does anyone have difficulty doing errands alone such as visiting a } \\
\text { doctor's office or shopping? }\end{array}$ \\
\hline $\begin{array}{l}\text { Work-activity limitation } \\
\text { (CPS-ASEC) }\end{array}$ & $\begin{array}{l}\text { Does anyone in this household have a health problem or disability which prevents them from working or which limits the kind } \\
\text { or amount of work they can do? }\end{array}$ \\
\hline \multicolumn{2}{|l|}{ Employment question } \\
\hline \multirow{2}{*}{$\begin{array}{l}\text { Currently employed (CPS-BMS) } \\
\text { Worked at least } 52 \text { hours in the } \\
\text { prior calendar year (CPS-ASEC) }\end{array}$} & Last week, did [person] do any work for either pay or profit? \\
\hline & $\begin{array}{l}\text { Work hours }>=52 \text {.To construct this variable, use the following two questions: (1) During [the previous calendar year] in how } \\
\text { many weeks did [person] work even for a few hours? Include paid vacation and sick leave as work, and (2) In the weeks that } \\
\text { [person] worked [the previous calendar year], how many hours did [person] usually work per week? }\end{array}$ \\
\hline $\begin{array}{l}\text { Worked full-time, full-year in the } \\
\text { prior calendar year (CPS-ASEC) }\end{array}$ & $\begin{array}{l}\text { Work hours per week >= } 35 \text { and work weeks per year >=50. To construct this variable, use the following two questions: (1) } \\
\text { During [the previous calendar year] in how many weeks did [person] work even for a few hours? Include paid vacation and sick } \\
\text { leave as work, and (2) in the weeks that [person] worked [the previous calendar year], how many hours did [person] usually } \\
\text { work per week? }\end{array}$ \\
\hline \multicolumn{2}{|l|}{ Program participation question } \\
\hline \multirow{2}{*}{$\begin{array}{l}\text { Social Security Disability } \\
\text { Insurance (CPS-ASEC) } \\
\text { Supplemental Security Income, } \\
\text { (CPS-ASEC) }\end{array}$} & $\begin{array}{l}\text { Did (you/name) receive Social Security? [If yes] what were the reasons (you/name) (was/were) getting Social Security income } \\
\text { last year? [retired; disabled (adult or child); widowed; spouse; surviving child; dependent child; on behalf of surviving, } \\
\text { dependent, or disabled child(ren); other (adult or child). Respondents were allowed two reasons. }\end{array}$ \\
\hline & $\begin{array}{l}\text { Did (you/name) receive SSI? [If yes] what were the reasons (you/name) (was/were) getting Supplemental Security Income last } \\
\text { year? [disabled (adult or child); blind (adult or child); on behalf of a disabled child; on behalf of a blind child; other (adult or } \\
\text { child)]. Respondents were allowed two reasons. }\end{array}$ \\
\hline
\end{tabular}

